\title{
MATERIAL REMOVAL MODE IN 3D MICRO USM
}

\author{
Y. Chen ${ }^{1}$, Z. Yu ${ }^{1 *}, \mathrm{G} . \mathrm{Li}^{2}, \mathrm{~S}$. Lei1, N. Wataru2 \\ ${ }^{1}$ Dalian University of Technology, 2 Linggonglu, Ganjingzi District, Dalian, 116024, China \\ ${ }^{1}$ Tokyo university of Agriculture and Technology, 2-24-16 Naka-cho, Koganei-shi, Tokyo 184-8588, Japan \\ *Corresponding author; e-mail: zyu@dlut.edu.cn
}

\begin{abstract}
Ultrasonic machining (USM) is known for its ability of processing brittle and hard materials such as silicon, glass and quartz. Usually, material removal in conventional USM is in brittle mode. The machined surface is covered with sharp tips and edges. In micro USM, the size of machined feature is less than $1 \mathrm{~mm}$. Different from the conventional USM, in micro USM, it was found that the machined surface is flat and smooth under certain machining conditions. This indicates that the ductile material removal mode exists in micro USM. Based on the experimental observation, the surface roughness, $R_{\text {pk, }}$ is used to identify the existence of ductile material removal mode in micro USM. The impact force of a single abrasive particle is calculated based on the elastic theory and crack generation. In this paper, 3D micro cavities were machined in quartz by micro USM under different machining conditions. Machined bottom surfaces were measured. Experimental results indicate that the brittle and ductile material removal modes are achievable by controlling the static load of micro USM.
\end{abstract}

\section{Keywords:}

Micromachining; Ultrasonic vibration; Material removal mode; 3D micro cavity; Surface roughness

\section{INTRODUCTION}

Micro ultrasonic machining (Micro USM), as an unconventional machining method, is widely used in the fine machining of hard and brittle materials, such as silicon, quartz and glass regardless of electrical and chemical properties of material [Thoe 2003]. There are two kinds of removal mode in the processing of hard and brittle materials: ductile mode and brittle mode. The removal mode of brittle materials changes with the depth of cut. Based on the brittle fracture of the surface, the material removal mode caused by material shedding changes to the ductile removal mode caused by elastic and plastic deformation of the surface. Consequently the surface also tends to be smooth. There is a transition mode between ductile mode and brittle mode [Shimada 1995].

$Z$. Yu et al. studied the effect of debris accumulation on material removal rate and surface roughness, and established the corresponding mathematical model to describe the influence of particles in the work area [Yu 2006]. Jiawen Song et al. found that the surface roughness $R_{p k}$ value was suitable to be identifying the removal mode in micro USM by processing micro-holes on $<100>$ faces of monocrystalline silicon. When the $R_{p k}$ value is larger than $500 \mathrm{~nm}$, the workpiece surface presents a brittle removal mode. When the $R_{p k}$ value is between $450 \mathrm{~nm}$ and $500 \mathrm{~nm}$, the workpiece is removed in the transition mode. When $R_{p k}$ is less than $450 \mathrm{~nm}$, the workpiece surface presents ductile removal characteristics [Song 2014]. Guodong Li et al. established a theoretical model to identify the removal mode of micro USM by machining micro-holes on the $<100>$ face of monocrystalline silicon and quartz crystal. It has been verified that $R_{p k}$ value was suitable for identifying the removal mode of micro USM [Li 2016]. Micro USM is able to generate 3D micro features in brittle and hard materials [Yu 2004]. In 3D micro USM, the tool is controlled to move along the designed tool paths, which is different from the hole drilling up-down tool path. The removal mode of micro USM influences on the material removal rate and surface quality. In brittle mode, the material removal rate is larger than that in ductile mode, while the surface quality is worse than that in ductile mode. It is necessary to study the influence of material removal mode in 3D micro USM.

In this paper, after calculating the indentation volume thresholds for radial and lateral crack under different material removal modes, the corresponding impact force of single abrasive particle is calculated based on the elastic theory. The static load used to control micro USM process is obtained based on the concentration of slurry. To verify the achievable material removal mode in micro USM, static loads under different machining conditions are calculated and 3D micro cavities in quartz are machined. Machined bottom surfaces were measured. Experimental results are analyzed and discussed. Comparing the experimental results with the theoretical values, it was found that the brittle and ductile material removal modes are achievable by controlling the static load in 3D micro USM.

\section{DATA CALCULATION}

\subsection{USM principle}

Fig. 1 shows the schematic of micro USM. In USM, the abrasive particles are vibrated between the tool and workpiece by a high frequency vibration. The material is 
mainly removed by the direct hammering of the abrasive particles against the workpiece surface.

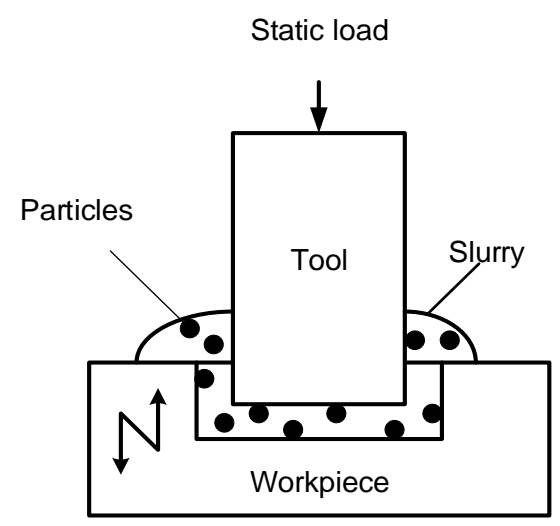

Fig. 1: Schematic of micro USM.

\subsection{The model of material removal in micro USM}

T.C.Lee observed the abrasive particles acting on the workpiece surface are similar to indenters by high speed photography [Lee 1997]. It is helpful to study the material removal mode in micro USM using indentation of brittle materials. In the indentation test and indentation fracture as shown in Fig. 2, the formation of radial and lateral crack can be described as (a) an inelastic deformation zone formation under a sharp particle; (b) at some threshold, radial/median crack is formed, with the indentation force increasing; (c) an increase in load causes growth of the median crack; (d) the median crack begins closing, on unloading; (e) with the particle removal, lateral cracks begin to develop; (f) upon complete unloading, lateral cracks continue extend toward specimen surface [Lawn 1975].

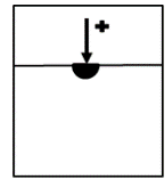

(a)

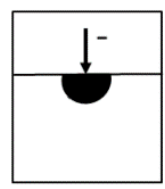

(d)

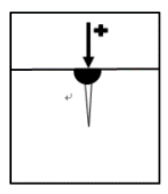

(b)

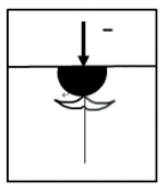

(e)

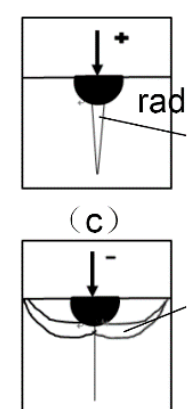

(f) ial/median crack

lateral cracks

Fig. 2: Schematic of vent crack formation under point indentation. during loading + , during unloading -.

The inelastic deformation zone can be defined by the indentation pressure, $P$, and the indentation volume $\delta V$, and plastic zone exhibits spherical symmetry, regardless of indenter geometry [Chiang 1982].

P. J. Slikkerveer summarized the former results and concluded that the cracks threshold for the radial/median cracks and laterals can be calculated by equation (1) and (2) [Slikkerveer 1998].

$$
\begin{aligned}
& \delta V_{D}=\left(\frac{3}{2 \pi}\right)^{3} \frac{\mu^{6}}{\beta^{6}} \frac{E^{\frac{3}{2}} K_{I C}^{6}}{H^{\frac{15}{2}}} \\
& \delta V_{B}=\frac{1}{3} \frac{\varsigma_{0}^{\frac{3}{2}}}{\alpha^{\frac{1}{2}} A^{3}} \frac{E^{\frac{3}{2}} K_{I C}^{6}}{H^{\frac{15}{2}}}
\end{aligned}
$$

$\delta V_{D^{-}}$the indentation volume threshold for radial/median cracks, $\delta V_{B^{-}}$the indentation volume threshold for lateral cracks, $K_{I C^{-}}$the fracture toughness of the workpiece, $\mu$ is a fit constant by least square fit, $H$ - the hardness, $\beta$ - the factor a dimensionless constant independent of material properties and indenter shape, value of $\beta$ Marshall calculated from fits of crack lengths of Anstis et al. [Anstis 1981], కo- the factor is fitted on experiment with Vickers indenters, $A$ - the factor describes the shape of the chip of material above the lateral crack. Marshall et al. concluded that the quarter plate model was the most appropriate [Marshall 1982].

There are 3 kinds of material removal modes in micro USM. The removal mode also varies with the change of the volume of indentation. The material removal mode in micro USM follows the following rules:

1. $\delta \mathrm{V}<\delta V_{\mathrm{D}}$, ductile mode.

2. $\delta V_{D}<\delta \mathrm{V}<\delta V_{B}$, brittle-ductile transition mode.

3. $\delta \mathrm{V}>\delta \mathrm{V}_{\mathrm{B}}$, brittle mode.

\subsection{Data calculating}

In the micro USM, the indentation volume $\delta V$ is calculated by indentation depth $\delta$ using equation (3). The indentation depth $\delta$ is calculated by maximum impact force $F$ using equation (4). The equations (3) and (4) are based on assumptions that abrasive particles are incompressible and identical spheres with same size [Yu 2006]. These assumptions are consistent with the requirement for value of $\beta$. The indentation in micro USM is shown in Fig. 3.

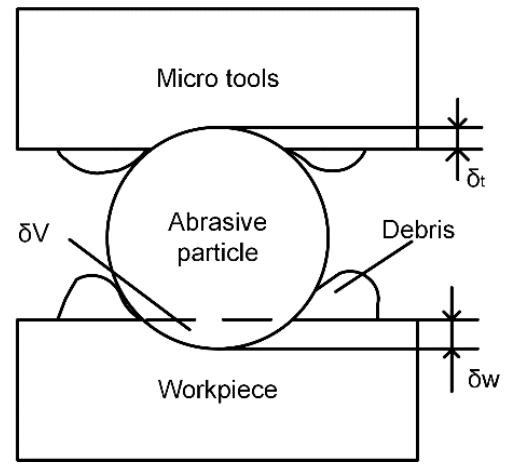

Fig. 3: The indentation in micro USM.

$$
\begin{aligned}
& \delta V=\frac{1}{3} \pi\left(3 r-\delta_{w}\right) \delta_{w}{ }^{2} \\
& \delta=\left(\frac{9 \pi^{2} F^{2} k^{2}}{16 r}\right)^{\frac{1}{3}}
\end{aligned}
$$

$\delta$ - the indentation depth under the impact force $F, \delta_{w}$ the indentation depth of workpiece, $F$ - maximum impact force of one particle during one cycle of vibration, $k$ - factor ( $\left.k=\frac{1-v^{2}}{\pi E}\right), v$ - Poisson's ratio, $E$ - modulus of elasticity, $r$ radius of particle.

Therefore, the ductile threshold force, $F_{D}$, and the indentation depth, $\delta_{D}$, are calculated by equations (1), (3) and (4). The brittle threshold force, $F_{B}$, and the indentation depth, $\delta_{B}$, are calculated by equations (2), (3) and (4).

In this study, the workpiece material is quartz crystal, the tool material is tungsten and the abrasive particles are polycrystalline diamond powder, which are consistent with precious experimental conditions [Li 2016]. Quartz parameters are listed in Tab. 1. The calculated corresponding forces and depths are listed in Tab. 2. 
Tab. 1: Quartz parameters.

\begin{tabular}{cc}
\hline parameters & value \\
\hline $\mathrm{K}_{\mathrm{IC}}$ & $0.66 \mathrm{MPa} \cdot \mathrm{m}^{1 / 2}$ \\
$\mu$ & 0.63 \\
$\mathrm{H}$ & $13.9 \mathrm{Gpa}$ \\
$\beta$ & 0.096 \\
$\zeta_{0}$ & $1.2 \times 103$ \\
$\mathrm{~A}$ & 0.75 \\
$\mathrm{v}$ & 0.1 \\
\hline
\end{tabular}

The quartz parameters used in calculation are from [Slikkerveer 1998, Anstis 1981, Marshall 1982, Guzzo, 2000, Li 2016].

Tab. 2: Indentation threshold depth and force.

\begin{tabular}{cllll}
\hline $\mathbf{r}(\boldsymbol{\mu} \mathbf{m})$ & $\delta_{\mathrm{D}}(\boldsymbol{\mu} \mathbf{m})$ & $\mathrm{F}_{\mathrm{D}}(\mathbf{g})$ & $\boldsymbol{\delta}_{\mathrm{B}}(\boldsymbol{\mu} \mathbf{m})$ & $\mathbf{F}_{\mathrm{B}}(\mathbf{g})$ \\
\hline 0.25 & 0.0529 & 0.0871 & 0.08882 & 0.1894 \\
0.75 & 0.0297 & 0.0633 & 0.0305 & 0.1331 \\
\hline
\end{tabular}

Micro USM is a dynamic processing in which the impact force varies within a certain range. The ductile threshold force, $F_{D}$, and the brittle threshold force, $F_{B}$, in Tab. 2 are theoretical values. To apply theoretical values in micro USM, they have to be modified using the force correction coefficient $K=4.36$ [ $\mathrm{Li} 2016$ ]. The threshold force, $F$, in the micro USM is calculated by equation (5). Results are listed in the Tab. 3. The measured force in micro USM is the average value of impact force, as shown in Fig. 4. Abrasive particles from to to $t_{1}$ contact with the workpiece. It is necessary to convert the threshold force, $F$, into the average force of a single abrasive particle, $F_{\text {avg }}$, by equation (6). The average forces of a single abrasive particle are listed in the Tab. 3.

$F^{\prime}=F / K$

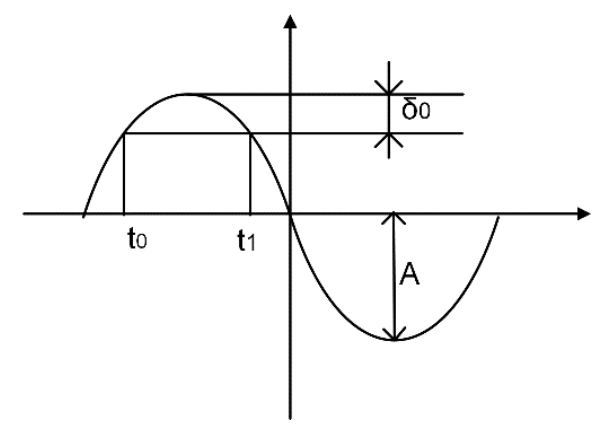

Fig. 4: Indentation depth and contact time of a particle in one cycle of vibration.

$2 F\left(\frac{1}{4 f}-\frac{\arcsin \left(1-\frac{\delta_{0}}{A}\right)}{2 \pi f}\right)=\frac{F_{\text {avg }}}{f}$

$f$ - frequency of vibration $(f=35.5 \mathrm{kHZ}), R_{0}$ - radius of tool $\left(R_{0}\right.$ $=50 \mu \mathrm{m})$.

Tab. 3: Threshold force and average force.

\begin{tabular}{ccccc}
\hline $\mathbf{r}(\boldsymbol{\mu m})$ & F $_{\mathrm{D}}{ }^{\prime}(\mathbf{g})$ & F Davg $_{(\mathbf{g})}$ & $\mathbf{F}_{\mathrm{B}}{ }^{\prime}(\mathbf{g})$ & $\boldsymbol{F}_{\text {Bavg }}(\mathbf{g})$ \\
\hline 0.25 & 0.01998 & 0.00146 & 0.0434 & 0.00412 \\
0.75 & 0.0145 & 0.0006985 & 0.0305 & 0.00214 \\
\hline
\end{tabular}

To control the micro USM, the tool move up-down based on the static load which is the sum of average force of all abrasive particles involved in machining. To obtain the static load, the number of particles, $N$, in working area is necessary to calculate. The number of particles is calculated by equation (7) and results are listed in the Tab. 4 [Yu 2006]. The static load rang of different material removal modes during machining are listed in the Tab. 5.

$$
N=\frac{3 R_{0}^{2}}{2 \mathrm{r}^{2}\left(1+\frac{\rho}{c}\right)}
$$

$\rho$ - specific gravity of abrasive particle $(\rho=3.47), c$ - weight concentration of particles $(c=1 \%)$.

Tab. 4: The number of abrasive particles.

\begin{tabular}{cc}
\hline $\mathbf{r}(\boldsymbol{\mu m})$ & $\mathbf{N}$ \\
\hline 0.25 & 172 \\
0.75 & 20 \\
\hline
\end{tabular}

Tab. 5: Static load rang of different modes.

\begin{tabular}{ccc}
\hline $\mathbf{r}(\boldsymbol{\mu m})$ & $\begin{array}{c}\text { ductile static load } \\
(\mathbf{g})\end{array}$ & $\begin{array}{c}\text { brittle static load } \\
(\mathbf{g})\end{array}$ \\
\hline 0.25 & $<0.26$ & $>0.71$ \\
0.75 & $<0.014$ & $>0.043$ \\
\hline
\end{tabular}

It can be found in Tab. 5 that the abrasive particle size of $0.5 \mu \mathrm{m}$ is suitable for ductile removal mode and the abrasive particle size of $1.5 \mu \mathrm{m}$ is suitable for brittle removal mode.

\section{EXPERIMENTAL VALIDATION}

\subsection{Experimental equipment}

Fig. 5 shows the self-developed experimental equipment of micro USM. The main components of equipment include: $X Y Z$ stages with the resolution of $0.1 \mu \mathrm{m}$; an electronic balance used for monitoring the static force during machining with the resolution of $1 \mathrm{mg}$; a wire electrical discharge grinding (WEDG) unit used for preparing tools [Masuzawa 1985]; the CCD camera used for observing the tool and micro USM; a set of ultrasonic system including an ultrasonic generator and an ultrasonic transducer and a set of computer system.

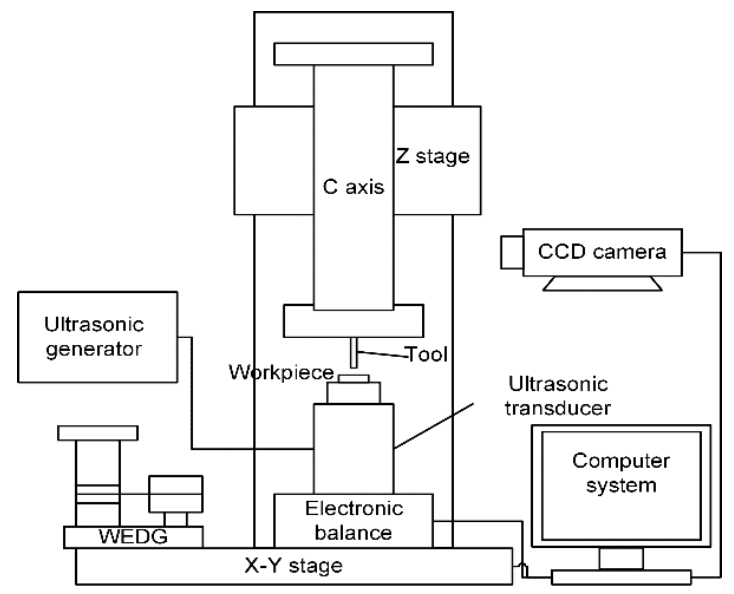




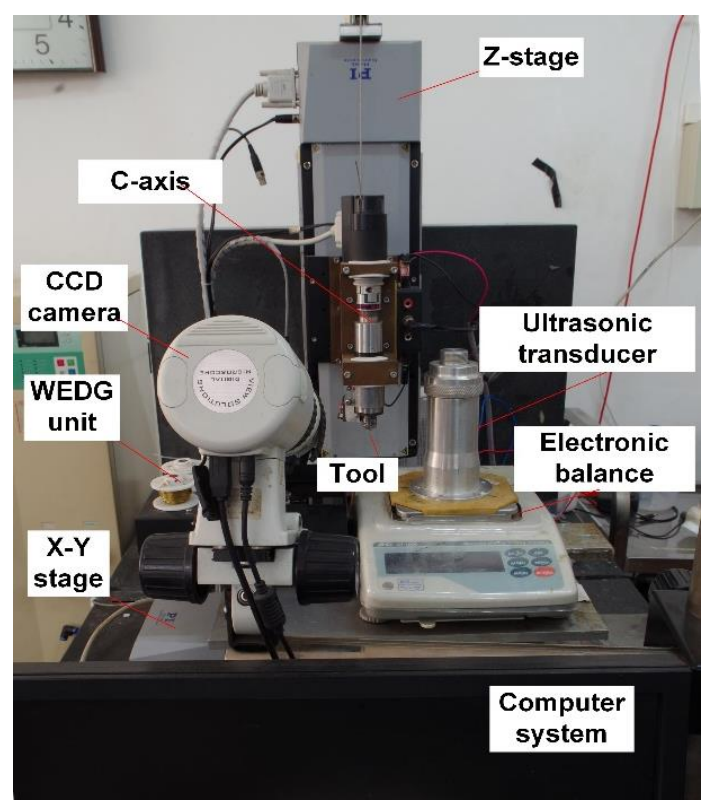

Fig. 5: The self-developed experimental equipment.

\subsection{Experimental parameters and conditions}

To obtain the relative volume wear rate of tools under different machining conditions of micro USM, extensive experiments are carried out. A commercial CAD/CAM software is used to design the $3 D$ cavity and generate machining paths. The tool paths are regenerated based on the uniform method.

Fig. 6 is the designed 3D cavity with the top square side length of $510 \mu \mathrm{m}$, the bottom side length of $350 \mu \mathrm{m}$, height of $80 \mu \mathrm{m}$ and $45^{\circ}$ of side surface. The cavity is machined layer-by-layer with a layer thickness of $1 \mu \mathrm{m}$. Scan pattern of the tool path is shown in Fig. 7. Based on Tab. 5, the static load setting and the corresponding tool wear ratio are listed in Tab. 6 [Yu 2004].

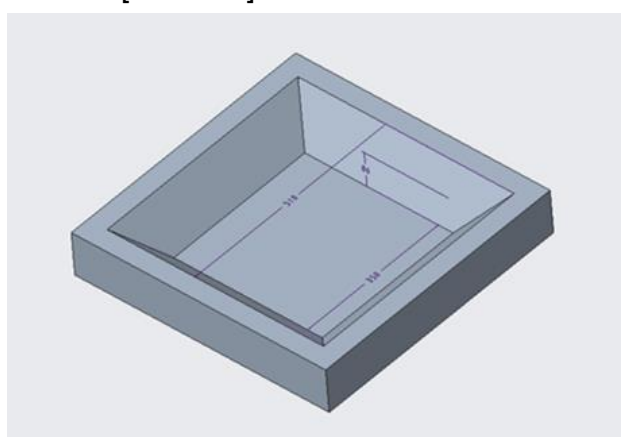

Fig. 6: Designed part.

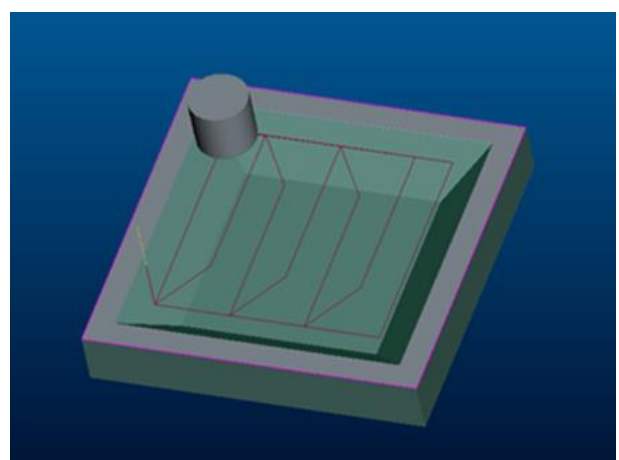

Fig. 7: Tool paths.
Tab. 6: Static load setting and tool wear ratio.

\begin{tabular}{ccc}
\hline $\mathbf{r}(\boldsymbol{\mu m})$ & $\begin{array}{c}\text { static load range } \\
\text { setting }(\mathbf{g})\end{array}$ & tool wear ratio \\
\hline 0.25 & $0-0.25$ & $6.1 \%$ \\
0.75 & $0.1-3$ & $11.8 \%$ \\
\hline
\end{tabular}

The moving speed of the tool within one layer machining is controlled using the electronic balance to keep the machining force within the desired range. The experimental conditions are listed in Tab. 7 and Tab. 8.

Tab. 7: Machining parameters of micro tool.

\begin{tabular}{ll}
\hline experimental parameters & settings \\
\hline the open voltage & $80 \mathrm{v}$ \\
tool diameter & Around $100 \mu \mathrm{m}$ \\
the length of tool & $700 \mu \mathrm{m}$ \\
capacitance in rough machining & $3300 \mathrm{pf}$ \\
capacitance in finish machining & $220 \mathrm{pf}$ \\
tool material & Tungsten \\
dielectric & Kerosene \\
rotating rate of tool & $600 \mathrm{r} / \mathrm{min}$ \\
\hline
\end{tabular}

Tab. 8: Machining parameters of micro USM.

\begin{tabular}{ll}
\hline experimental parameters & settings \\
\hline vibration frequency & $35.5 \mathrm{kHz}$ \\
vibration amplitude & $2 \mu \mathrm{m}$ \\
abrasive particle material & $\begin{array}{l}\text { Polycrystalline } \\
\text { diamond (PCD) }\end{array}$ \\
abrasive particle size & $0.5,1.5 \mu \mathrm{m}$ \\
abrasive particle specific gravity & 3.47 \\
abrasive particle concentration & $1 \%$ to water \\
tool material & Tungsten \\
tool diameter & Around $100 \mu \mathrm{m}$ \\
workpiece material & Z-cut samples of \\
& quartz crystal \\
rotating rate of tool & $600 \mathrm{r} / \mathrm{min}, 0 \mathrm{r} / \mathrm{min}$ \\
\hline
\end{tabular}

\section{EXPERIMENTAL RESULTS AND DISCUSSION}

\subsection{Machined cavity, surface and tools}

Figs. 8 (a) and (b) show the machined cavities in brittle and ductile mode. The cavity was machined $3.6 \mathrm{hrs}$ in brittle mode and $8.4 \mathrm{hrs}$ in ductile mode. Although it was machined in 80 layers, the thermal deformation of experimental structure might caused the side surface machined in several large layers. The other reason caused the large layers on the side surface of cavity might be the electron scanning during SEM image generation. 


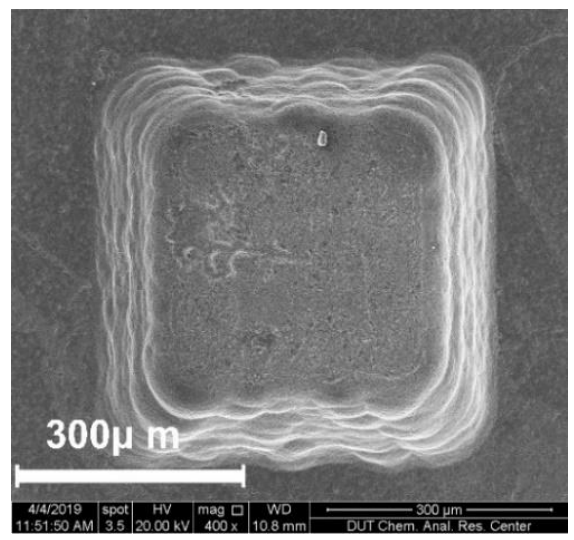

(a) In brittle mode.

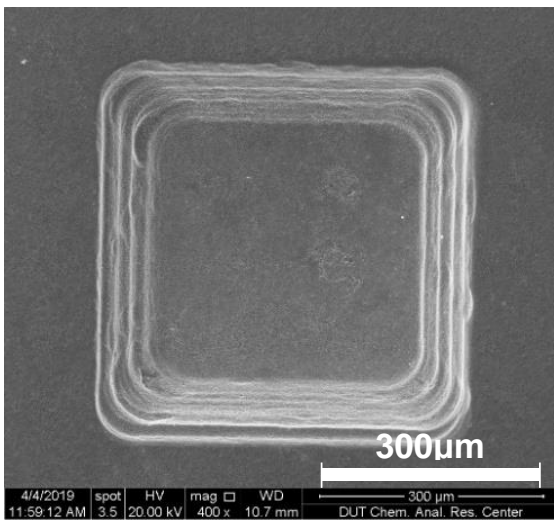

(b) In ductile mode.

Fig. 8: Machining 3D cavity.

Figs. 9 (a) and (b) show the tool after 3D micro USM. It can be seen that tools were worn uniformly. The tool wear length was calculated by the position difference using contact force of $0.02 \mathrm{~g}$ at the same reference point of workpiece surface before and after machining. The tool wear length was $176.4 \mu \mathrm{m}$ in brittle mode and $86.3 \mu \mathrm{m}$ in ductile mode, respectively.

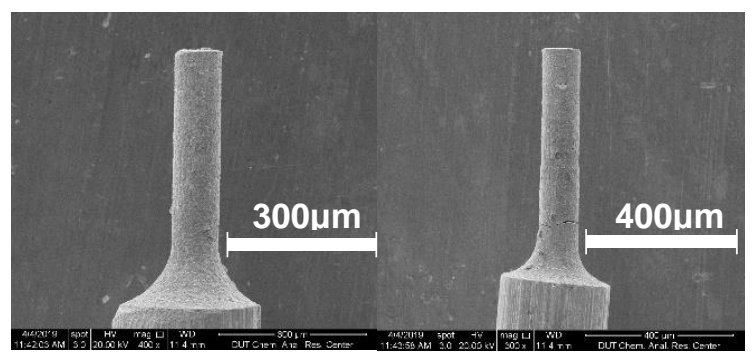

(a) Brittle mode.

(b) Ductile mode.

Fig. 9: The tool after micro USM.

Fig. 10 is an enlarged view of the bottom surface processed in the ductile removal mode using abrasive particles of $0.5 \mu \mathrm{m}$ in size. Fig. 11 shows the enlarged bottom surface processed in the brittle removal mode using abrasive particles of $1.5 \mu \mathrm{m}$ in size. It can be found that the surface is smooth without obvious sharp and deep pit in the ductile mode in Fig. 10 while there are obvious sharp tips and pits on the surface in the brittle mode in Fig. 11.

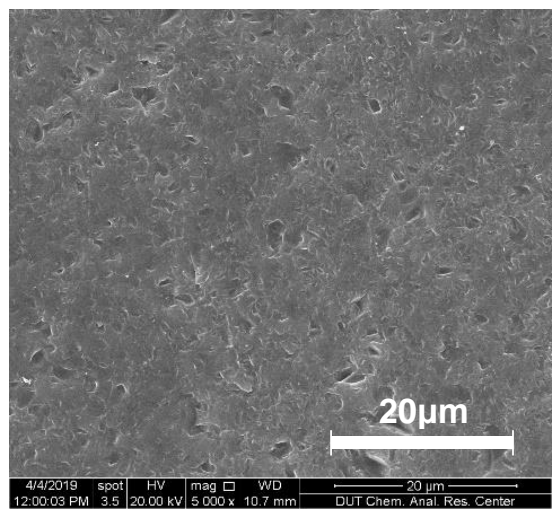

Fig. 10: Machined surfaces in the ductile removal mode.

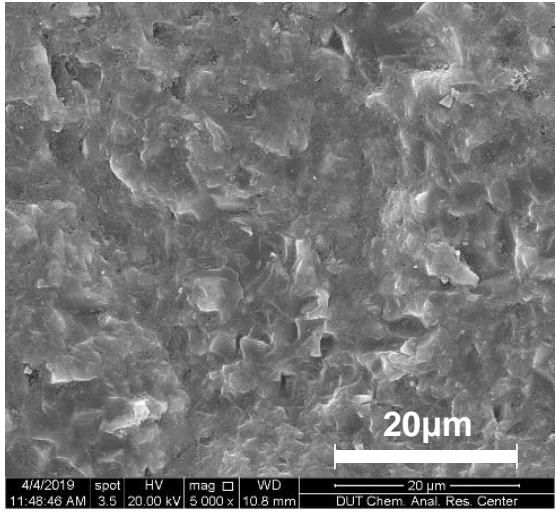

Fig. 11: Machined surfaces in the brittle removal mode.

\subsection{Results discussion}

In previous study of USM of monocrystalline silicon $<100>$ faces, it was found that the material removal mode can be identified by surface roughness, Rpk [Song 2014]. For quartz material, when the $R_{\text {pk }}$ value is larger than $350 \mathrm{~nm}$, the machined surface shows the brittle removal mode; when the $R_{p k}$ value is less than $350 \mathrm{~nm}$, the machined surface shows the existence of ductile removal mode [ $\mathrm{Li}$ 2016].

In 3D micro USM, the material is removed by layer-by-layer. The machined bottom surfaces were measured using a set of white light interferometer. The bottom surface quality of 3D cavity depends on the static load of the last layer. The bottom surface roughness, $R_{p k}$, is average values of five locations on the bottom surface of a cavity. Fig. 12 shows the measured surface roughness values under machining conditions listed in Tabs. 5 and 8. No. in Fig. 12 is the sample number.

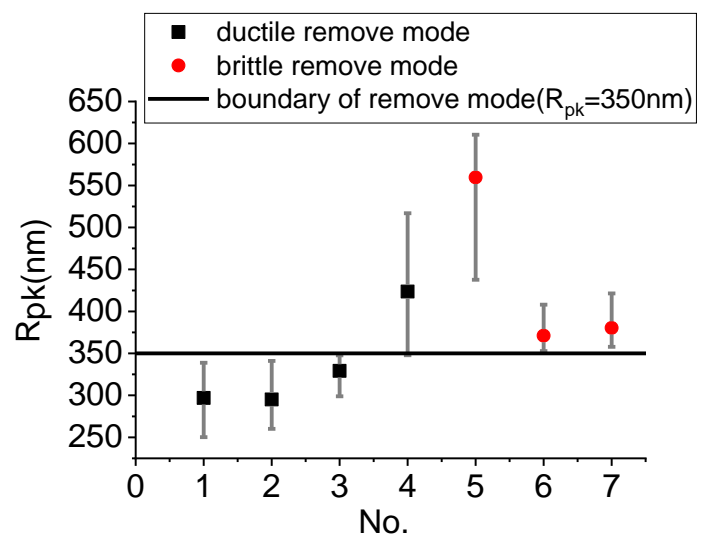

Fig. 12: Rpk value of the workpiece surface. 
The average static load, $L_{a v g}$, in Tab. 9 is calculated based on recorded static load in the final layer. Although the static load was controlled based on static load setting of different removal mode in Tab. 5 , measured $R_{p k}$ value of sample No. 4 in Fig. 12 is larger than $350 \mathrm{~nm}$, the threshold surface roughness $R_{p k}$ value of ductile removal mode. The corresponding average static load in Tab. 9 is less than static load setting of ductile removal mode $0.25 \mathrm{~g}$ in Tab. 5 .

Tab. 9: Static load of the last layer.

\begin{tabular}{ccccc}
\hline No. & $\begin{array}{c}\text { thickness } \\
(\boldsymbol{\mu m})\end{array}$ & $\mathbf{r}(\boldsymbol{\mu m})$ & $\begin{array}{c}\text { tool } \\
\text { rotation }\end{array}$ & Lavg $(\mathbf{g})$ \\
\hline 1 & 1 & 0.25 & $\mathrm{Y}$ & 0.228 \\
2 & 1 & 0.25 & $\mathrm{Y}$ & 0.0414 \\
3 & 1 & 0.25 & $\mathrm{~N}$ & 0.0925 \\
4 & 1 & 0.25 & $\mathrm{~N}$ & 0.232 \\
5 & 1 & 0.75 & $\mathrm{Y}$ & 0.062 \\
6 & 1 & 0.75 & $\mathrm{~N}$ & 0.227 \\
7 & 1 & 0.75 & $\mathrm{~N}$ & 0.596 \\
\hline
\end{tabular}

To understand this phenomenon, static load record of sample No. 4 for the last layer machining is shown in Fig. 13. Fig. 14 shows the corresponding SEM of the machined surface. It can be seen that the machined surface covered with sharp edges and deep pits. During machining of sample No. 4, there was no tool rotation. The machining process of last layer in sample No. 4 was unstable. On the other hand, abrasive particles are suspended in slurry. In 3D micro USM, they might be unevenly distributed in machining area, resulting in unevenly material removal.

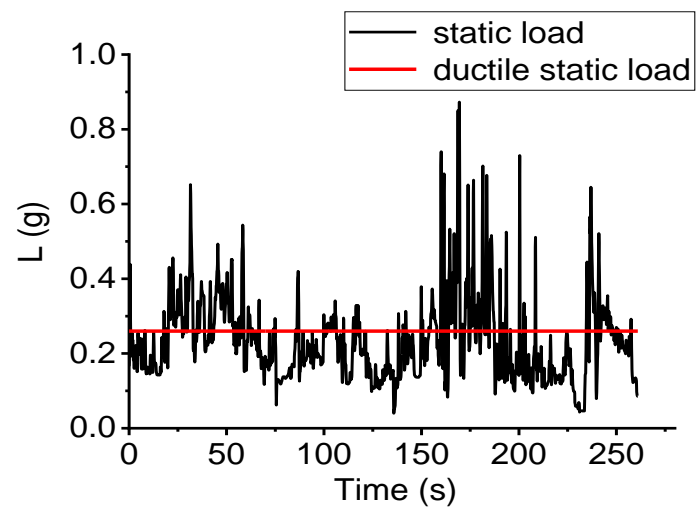

Fig. 13: Static load record of last layer of sample No. 4.

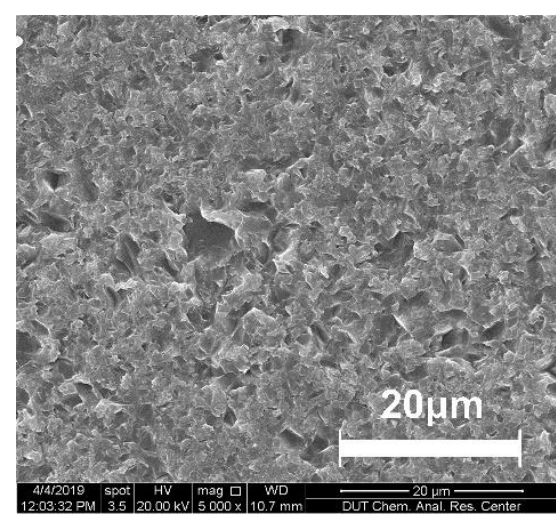

Fig. 14: Machined surface of sample No. 4.

\section{SUMMARY}

This paper presented 3D micro USM under different material removal modes. Based on elastic theory and crack generation theory, the impact force of single particle abrasive is calculated and the corresponding static pressure under different removal modes is obtained. By controlling the static pressure, 3D cavities were obtained under different removal modes of micro USM in quartz. The surface roughness $R_{p k}$ is used to identify the removal method. The experimental results indicates that the calculated static load based on theories can be used to control 3D USM under different material modes.

\section{ACKNOWLEDGMENTS}

Authors are thankful for the support from the National Science Foundation of China (NSFC) (No.51475075 and 91860134)

\section{REFERENCES}

\section{Paper in a journal:}

[Thoe 1998] Thoe, T.B., et al. Review on ultrasonic machining, International Journal of Machine Tools and Manufacture, 1998, Vol.380, No.4., pp 239-255. ISSN 0890-6955

[Shimada 1995] Shimada, S., et al. Brittle-Ductile Transition Phenomena in Micro indentation and Micromachining. Annals of the CIRP, 1995, Vol.44, No. 1., pp 523-526. ISSN 0007-8506

[Yu 2006] Yu, Z.Y., et al. Influence of Debris Accumulation on Material Removal and Surface Roughness in Micro Ultrasonic Machining of Silicon. Annals of the CIRP, 2006, Vol.55, No.1., pp 201-204. ISSN: 0007-8506

[Li 2016] Li, G.D., et al. Material Removal Modes of Quartz Crystals by Micro USM. Procedia CIRP, 2016, Vol.42, pp 842-846. ISSN: 2212-8271

[Yu 2004] Yu, Z.Y., et al. Study of 3D micro-ultrasonic machining. Journal of Manufacturing Science and Engineering, 2004, Vol.126, No.4., pp 727-732. ISSN: 1087-1357

[Lee 1997] Lee, T.C. and Chan, C.W. Mechanism of the ultrasonic machining of ceramic composites. Journal of Materials Processing Tech., 1997, Vol.71, No.2., pp 195201. ISSN: 0924-0136

[Lawn 1975] Lawn, B. and Wilshaw, R. Indentation fracture: principles and applications. Journal of Materials Science, 1975, pp 1049-1081

[Chiang 1982] Chiang, S.S., et al. The response of solids to elastic/plastic indentation. I. Stresses and residual stresses. Journal of Applied Physics, 1982, Vol.53, No.1., pp 298-311. ISSN: 0021-8979

[Slikkerveer 1998] Slikkerveer, P.J. and Bouten, P.C.P., Erosion and damage by sharp particles. Wear, 1998, Vol.217, No.2., pp 237-250. ISSN: 0043-1648

[Anstis 1981] Anstis, G.R., et al. A Critical Evaluation of Indentation Techniques for Measuring Fracture Toughness: I, Direct Crack Measurements. Journal of the American Ceramic Society,1981, Vol.64, pp 533-538

[Marshall 1982] Marshall, D.B., et al. Elastic/Plastic Indentation Damage in Ceramics: The Lateral Crack System. Journal of the American Ceramic Society, 1982, Vol.65, No.11., pp 561-566. ISSN: 0002-7820

[Guzzo 2000] Guzzo, P.L. and De Mello, J.D.B. Effect of crystal orientation on lapping and polishing processes of 
natural quartz. IEEE Transactions on Ultrasonics, Ferroelectrics, and Frequency Control, 2000, Vol.47, No.5., pp 1217-1227. ISSN: 0885-3010

[Masuzawa 1985] Masuzawa, T., et al. Wire Electrodischarge Grinding for Micromachining. CIRP AnnlsManufacturing Technology, 1985, Vol.48, No.1., pp 431434. ISSN: 0007-8506

\section{Paper in proceedings:}

[Song 2014] Song, J.W., et al. Study of Criterion of Material Removal Mode in Micro USM. International Conference on Micromanufacturing, Singapore, March, 2014. pp 63-71 